\title{
Determinants of polychlorinated aromatic hydrocarbons in serum in three age classes-Methodological implications for human biomonitoring is
}

\author{
Elly Den Hond ${ }^{\mathrm{a}, *}$, Eva Govarts $^{\mathrm{a}}$, Liesbeth Bruckers ${ }^{\mathrm{b}}$, Greet Schoeters ${ }^{\mathrm{a}}$ \\ ${ }^{a}$ Flemish Institute of Technological Research (VITO), Environmental toxicology, Boeretang 200, $2400 \mathrm{Mol}$, Belgium \\ ${ }^{\mathrm{b}}$ University of Hasselt, Interuniversity Institute for Biostatistics and statistical Bioinformatics, University Campus, Building D, 3590 Diepenbeek, Belgium
}

\section{A R T I C L E I N F O}

\section{Article history:}

Received 19 August 2008

Received in revised form

23 December 2008

Accepted 5 February 2009

Available online 10 March 2009

\section{Keywords:}

Human biomonitoring

Biomarkers of exposure

Polychlorinated aromatic hydrocarbons

(PCAH)

Pesticides

Polychlorinated biphenyls (PCBs)

\begin{abstract}
A B S T R A C T
Human biomonitoring provides an integrated measure for individual exposure to environmental pollutants. Better insight in inter-individual variability of biomarkers of exposure may help in the interpretation of biomonitoring studies.

The aim was to study the impact of outliers, determine the optimal unit for fat-soluble biomarkers in serum and quantify the major determinants for biomarkers of exposure to polychlorinated aromatic hydrocarbons (PCAHs) in three age groups.

Data were obtained from the Flemish Environment and Health Study (2002-2006). Marker PCBs (sum of $138,153,180$ ), hexachlorobenzene (HCB) and p,p'-DDE were measured in cord blood samples of 1196 newborns, in serum samples of 1679 adolescents (14-15 years) and 1583 adults (50-65 years).

Exclusion of influential outliers in multiple linear regression models lead to models that are better applicable to the general population. In terms of adjusted $R^{2}$, the regression model with the pollutant expressed in volume-based units and blood fat as a separate independent variable was superior compared to models with other units. We found highly consistent relationships between the serum concentration of PCAHs and blood fat, age, changes in body weight, animal fat in the diet, local vegetable consumption (HCB and p, $\mathrm{p}^{\prime}$-DDE only) and being breastfed as a baby (in adolescents only). The impact of sex and BMI differed by age.

For biomarkers of persistent pollutants that reflect long-term exposure, the relation between the covariates and the biomarkers can be well quantified.
\end{abstract}

(c) 2009 Elsevier Inc. All rights reserved.

\section{Introduction}

Biologic monitoring, i.e. human biomonitoring, is used to assess human exposures to environmental and workplace chemicals. Biomarkers of exposure take into account inter-individual differences in absorption, distribution, biotransformation, and excretion of a substance, which may be associated with differences in age, sex, height, weight, physiologic and nutritional status, duration of exposure, etc. Biomarkers of exposure assess the internal dose of a xenobiotic compound and are therefore

Abbreviations: 95\% CI, 95\% confidence interval; AMAP, Arctic Monitoring and Assessment Programmme; BMI, body-mass index; FFQ, food frequency questionnaire; HCB, hexachlorobenzene; IQ interquartile range; ln, natural logarithm; $\mathrm{Na}_{2}$-EDTA, sodium ethylenediaminetetraacetic acid; ns, not significant; PCAHs, polychlorinated aromatic hydrocarbons; PCBs, polychlorinated biphenyls; p, $\mathrm{p}^{\prime}$-DDE, p, $\mathrm{p}^{\prime}$-dichlorodiphenyldichloroethylene; $R_{\mathrm{a}}^{2}$, adjusted coefficient of determination; VIF, variance inflation factor

The study was approved by the medical ethical committee of the University of Antwerp (July 4, 2002).

* Corresponding author. Fax: +3214582657.

E-mail address: elly.denhond@vito.be (E. Den Hond). more likely to be directly associated with possible adverse health effects than external exposure monitoring results (Lauwerys and Hoet, 2001).

Between 2002 and 2006, a large human biomonitoring campaign was conducted in Flanders, the Dutch-speaking part of Belgium. As biomarkers of exposure to polychlorinated aromatic hydrocarbons (PCAHs), we studied the serum concentration of polychlorinated biphenyls (PCBs) (sum of marker PCB 138, 153 and 180) and serum concentrations of the organochlorine pesticides hexachlorobenzene (HCB) and p, $\mathrm{p}^{\prime}$-dichlorodiphenyldichloroethylene (p,p'-DDE) in more than 4400 participants of the general population including newborns $(n=1196)$, $14-15$-year-old teenagers $(n=1679)$ and adults between 50 and 65 years $(n=1583)$.

PCBs were first produced commercially in the 1920s, although it was not until the 1950s that industrial applications of PCBs increased substantially. They were used as hydraulic or transformer fluids, as plasticisers in paint, and in carbonless copying paper. In Belgium, the use of PCBs has been banned since 1986 and a PCB-elimination plan was designed to remove all PCB-containing devices by 2010. p, $\mathrm{p}^{\prime}-\mathrm{DDE}$ is the organic 
metabolite of DDT, a pesticide that has been used worldwide for decades to control insects in agriculture and insects that carry diseases such as malaria. Since 1979, DDT is forbidden in Belgium, but it is still allowed in developing countries with malaria. HCB is a persistent chlorinated pesticide that was mainly used to protect seeds and grains against fungus. It was also used in the production of fireworks, ammunition and synthetic rubber until the early seventies. PCBs, p,p'-DDE and HCB are lipophilic, persistent substances that have entered the environment and contaminated the food chain, most notably fish. They become biologically magnified in the food chain from soil and sediment to fish or animal feed, to dairy and meat products, and eventually to man where they accumulate in fat tissue. To a lesser extent, they contaminate dust, soil and water and reach men through inhalation and skin contact. In newborns, PCAHs are transferred from mother to their babies both prenatal (in utero) and postnatal via breastfeeding.

PCBs, p,p'-DDE and HCB have hormone-disrupting, immunedisrupting and carcinogenic properties. Previous studies in Belgium have estimated PCAH exposure in the general population, and have demonstrated significant relationships between current exposure levels and health effects (Den Hond et al., 2002; Staessen et al., 2001; Van Den Heuvel et al., 2002). Although PCBs, HCB and DDT are prohibited in Belgium and many efforts were done to control for contamination of the environment, it remains relevant to monitor the levels of these persistent compounds in the general population until concentrations have dropped below safe levels.

The Environment and Health study has delivered a large dataset with individual measurements of three PCAHs in three age groups and thus allows us to study a number of methodological aspects that are important in human biomonitoring studies. The aims of this study were to use the data of this large cohort to investigate in detail the impact of outliers on summary outcomes and regression models, to compare the use of fat-adjusted versus volume-based units, and to determine the major factors of interindividual variability of serum PCBs, HCB en p, $\mathrm{p}^{\prime}$-DDE in the three age groups.

\section{Materials and methods}

\subsection{Environment and health study}

Between 2002 and 2006 we have introduced in Flanders a human biomonitoring network, which includes measurement of biomarkers of exposure in combination with biomarkers of effect and individual health data. A biomarker of effect provides a measure for an early biological effect of altered function in the human body in reaction to environment pollutant exposure. Biomarkers of effect will not be studied in this publication.

Flanders is an industrialized region in the North of Belgium with 6 million inhabitants, it is densely populated and has a dense traffic network. Participants were systematically recruited in eight geographical areas covering $22 \%$ of the surface area of Flanders and $20 \%$ of the population. Two areas were urbanized (Antwerp city and Ghent city), four areas were characterized by industrial settings (Ghent and Antwerp harbor, non-ferro industry, chemical industry and areas around waste incinerators), one area had intensive fruit cultivation (fruit growing area) and one area was less densely populated and had no registered emissions (rural area). Three age groups were involved in the human biomonitoring study: newborns and their mothers, 14-15-year-old adolescents and adults between 50 and 65 . In total, about 4500 participants were systematically recruited. The recruitment campaign was scheduled over 3 years (2002-2004). Inclusion criteria for participation in the campaign were residing at least 5 years in the area, giving written informed consent and being able to fill in an extensive Dutch questionnaire. Participants were enrolled at random within primary sampling units. Twin pairs $(n=10)$ were allowed in the newborn study; in the adult study, spouses $(n=401)$ could also participate in the trial. By stratified sampling by study area, we selected 26 maternities, 42 secondary schools and 46 communities as primary sampling units for the newborn, adolescent and adult study, respectively. In the newborn study, $97 \%$ of the eligible mothers agreed to deliver cord blood and answer the questionnaire. In the adolescent and adult study, invitation letters were sent via the schools and by regular post. $71.6 \%$ of the adolescents and $47.5 \%$ of the adults replied to the invitation and, respectively $85.7 \%$ and $75.3 \%$ of those who answered, agreed to participate. The study was approved by the medical ethical committee of the University of Antwerp.

\subsection{Blood collection}

In newborns, minimal $30 \mathrm{~mL}$ cord blood was collected by leaving the umbilical cord blood running off in $50 \mathrm{~mL}$ polypropylene tubes filled with $0.5 \mathrm{~mL}$ sodium ethylenediaminetetraacetic acid $\left(\mathrm{Na}_{2}\right.$-EDTA) as anticoagulant. Cord blood was aliquoted and plasma was separated by centrifugation within $24 \mathrm{~h}$ in the maternity laboratories. The aliquoted samples were kept in the refrigerator and transported to the analytical laboratory within 1 week. After transport in cool boxes, the samples were stored at $-20^{\circ} \mathrm{C}$ until analysis.

Both in the adolescents and the adults, $40 \mathrm{~mL}$ of non-fasting peripheral blood was sampled. $\mathrm{Na}_{2}$-EDTA $(10 \% \mathrm{v} / \mathrm{v})$ was added to whole blood while serum was prepared by immediate centrifugation of the coagulated blood. Samples were kept in cool boxes and transported to the central laboratory within $24 \mathrm{~h}$ where they were stored at $-20^{\circ} \mathrm{C}$ until analysis.

\subsection{Measurements in cord blood}

Marker PCB 138, 153, 180 and the chlorinated pesticides HCB and p,p'-DDE were analyzed by gas chromatography equipped with an electron capture detector using the method of Gomara et al. (2002). In all three human biomonitoring campaigns, chemical analyses were performed by two labs. Both laboratories participated in the Arctic Monitoring and Assessment Programmme (AMAP) proficiency testing scheme (Institut National de Santé Publique, Quebec, Canada). Precision (relative standard deviation) was estimated using results of the ClinChek and AMAP samples and ranged between $6.7 \%$ and $9.3 \%$ for all compounds, with the exception of HCB (18.1\%). The limit of detection for all chlorinated compounds in plasma was $0.02 \mu \mathrm{g} / \mathrm{L}$. The plasma total lipid concentration was determined gravimetrically. In case no value could be obtained gravimetrically, total lipid concentration was calculated on the basis of routinely measured triglycerides and total cholesterol by the following formula: total lipids $=1.33 \times$ (triglycerides + cholesterol) $+50.5 \mathrm{mg} / \mathrm{dL}$ (Covaci et al., 2006). All laboratories involved in the analysis of biomarkers applied standard agreed quality control/quality assurance procedures.

\subsection{Questionnaire data}

All participants completed a self-administered extensive questionnaire, assessing information on lifestyle, dietary intake, use of tobacco and alcohol residence history, health, education, hobbies and occupation (if applicable). Before the study, the questionnaire was pre-tested in a group of adults and adolescents with a lower educational level. Questions were adapted to the comments of the test group.

Information from the questionnaire was carefully checked before it was used in the statistical analysis. Inconsistent answers or extreme outlying values in the answers were checked by re-contacting the participant by telephone. Body-mass index (BMI) of the mothers was calculated, based on self-reported height and weight before pregnancy. For adolescents and adults, height and body weight were measured according to a standardized protocol (WHO, 1995). Dietary intake was assessed via a semi-quantitative food frequency questionnaire (FFQ) as described in detail by Bilau et al. (2008). For each individual, dietary intake of fat from different sources was estimated in grams per day, for different sources of fat i.e. beef, pork, sheep, horse, chicken, turkey, cereals, yoghurt, milk, eggs, cheese cooking and frying fats, seafood (shrimps and mussels) and fish (lean, fatty, smoked and canned). Participants were asked whether they regularly use local food products (meat or vegetables); these answers were used as binary variables in the analysis.

\subsection{Statistical analysis}

Database management and statistical analyses were done with SAS software version 9.1 (SAS Institute Inc.).

Biomarkers below the detection limit $(0.02 \mu \mathrm{g} / \mathrm{L}$ for all compounds) were first replaced by half the detection limit, a method that is often applied in large human biomonitoring trials ((NCEH) 2005; Becker et al., 2008). Then, concentrations were expressed in molar units by using the following conversion factors: PCB congeners 138 and 153: $1 \mu \mathrm{g}=2.771 \mathrm{nmol}$; РCB congener $180: 1 \mu \mathrm{g}=2.530 \mathrm{nmol}$; $\mathrm{HCB}$ : $1 \mu \mathrm{g}=4.02 \mathrm{nmol}$; and p, $\mathrm{p}^{\prime}$-DDE: $1 \mu \mathrm{g}=3.14 \mathrm{nmol}$. Finally, marker PCBs in molar units were added.

Data that were not normally distributed, were natural logarithm (ln)transformed and described by their geometric means and $95 \%$ confidence intervals (95\% CIs). 
2.5.1. Multiple linear regression models of serum PCBs in adolescents and adults

Multiple linear regression models were built to identify the major determinants of the biomarker levels. In first instance, this was done for serum PCBs in adolescents and adults. For both age groups, separate models were investigated for different units of PCBs, i.e. (A) PCB concentration expressed in nmol/L without any adjustment for blood fat (volume-based units); (B) PCB concentration expressed in $\mathrm{nmol} / \mathrm{L}$ with blood fat $(\mathrm{mg} / \mathrm{dL})$ added as a separate explanatory variable in the model (volume-based units with adjustment for blood fat); and (C) PCB concentration expressed in $\mathrm{pmol} / \mathrm{g}$ blood fat (fat-based units). Possible covariates that determine inter-individual variation of the concentration of PCBs were listed based on a literature search. A multiple linear regression model was built including covariates significant at a $10 \%$ level in the univariate analyses. Important covariates were identified by stepwise regression procedures in which we set the $p$-value at 0.10 for the independent variables to enter and at 0.05 to stay in the model. The adjusted $R^{2}$ (coefficient of determination, $R_{a}^{2}$ ) of the obtained multiple linear regression models was used to select the 'best' model. This coefficient shows the proportion of variability in the biomarker values that is accounted for by this model, penalizing for the number of explanatory variables in the model.

Variance inflation factors (VIFs) were used to analyze the effects of multicollinearity. If the VIFs were larger than 10 multicollinearity was concluded.

The assumptions of normality, constancy of variance, independence (randomness) and linearity were checked with informal diagnostic plots and formal tests (White's General test for constancy of variance, Kolmogorov-Smirnov test for normality and the lack of fit test for linearity).

\subsubsection{Impact of outliers}

An observation is considered to be outlying with respect to its biomarker value when its value lies more than 1.5 times above or below the interquartile range (IQ $=$ the 75 th percentile-the 25 th percentile) (Grubbs, 1969; Moore and McCabe, 1999). The impact of outliers on the summary statistics was investigated. A case may also be outlying if it has dramatic effects on the multiple regression analysis. A case may be outlying with respect to its $Y$ value (biomarker value), its $X$ value (covariates in the model), or both. In a first step, we identified outlying cases based on the fitted model; outliers with respect to the response were assessed using the studentized deleted residuals and outliers with respect to the predictor variables were assessed using the leverages or the diagonal elements of the hat matrix. In a second step, specific methods (DFFITS and Cook's Distance) were used to detect if these outlying cases were influential, that is cases that heavily influenced the fitted model. Models were fitted with and without influential cases and it was studied whether exclusion of the influential cases significantly changed the regression parameters.

\subsubsection{Quantification of impact of determinants}

Quantitative relationships between the determinants and the biomarkers were calculated from the estimates of the multiple linear regression model, assuming that, when quantifying the relation of one covariate with the biomarker, all other covariates in the model are fixed at the population mean.

\section{Results}

Descriptive statistics and mean exposure values for the sum of marker PCBs, HCB and p, $\mathrm{p}^{\prime}$-DDE in the three study populations are given in Table 1.

\subsection{Choice of units: volume-based versus fat-based units}

Both in adolescents and in adults, we build multiple linear regression models to identify the determinants for interindividual variability of serum PCB levels. These regression models were constructed for different units of serum PCBs, i.e. serum PCBs in nmol/L without adjustment for blood fat (model A), serum PCBs in $\mathrm{nmol} / \mathrm{L}$ with blood fat as explanatory variable in the model (model B) and serum PCBs expressed in $\mathrm{pmol} / \mathrm{g}$ blood fat (model $C$ ). In both age groups, inclusion of blood fat in the analysis, either as an independent variable in the model (B) or as a correction factor in the formula (C), considerably increased the variability in serum PCB levels that is explained by the model (Table 2). In adolescents, very similar results were obtained with blood fat added as an independent variable in the model $\left(R_{\mathrm{a}}^{2}=0.43\right)$ and with fat-based units $\left(R_{\mathrm{a}}^{2}=0.44\right)$, demonstrating that both models explain a similar proportion of the variability in the model (43\% vs. $44 \%$ ). In adults, inclusion of blood fat as a separate variable in the model resulted in a considerably higher adjusted $R^{2}\left(R_{\mathrm{a}}^{2}=0.30\right)$ compared to a model with fat-based units $\left(R_{\mathrm{a}}^{2}=0.19\right)$, making the former model superior with respect to the variability that can be explained by the model. Overall, we conclude that the model with PCBs in volume-based units with blood fat as separate independent variable in the multiple regression model is superior to the other units and will therefore be used in all further analyses.

\subsection{Impact of outliers}

An observation may be outlying with respect to its biomarker values. For serum PCBs in $\mathrm{nmol} / \mathrm{L}$ in adolescents, 17 cases were found to be beyond the fences. Dropping these outlying cases from the study population resulted in a similar geometric mean and 95\% CI (mean: $0.779 \mathrm{nmol} / \mathrm{L}$; 95\% CI: 0.761-0.798 nmol/L) compared to the whole study population (mean: $0.781 \mathrm{nmol} / \mathrm{L}$; $95 \% \mathrm{CI}: 0.762-0.801 \mathrm{nmol} / \mathrm{L}$ ). In adults, 37 cases were identified as outlying. Here also, the geometric mean and confidence interval without the outlying cases (mean: $5.500 \mathrm{nmol} / \mathrm{L} ; 95 \% \mathrm{CI}$ : $5.396-5.605 \mathrm{nmol} / \mathrm{L}$ ) were comparable with those of the whole population (mean: $5.485 \mathrm{nmol} / \mathrm{L}$; $95 \% \mathrm{CI}$ : $5.370-5.603 \mathrm{nmol} / \mathrm{L}$ ).

A case may also be an outlier if it has dramatic effects on the regression coefficients in the linear regression models. In adolescents, 57 cases were found to be outlying with respect to the biomarker values while 55 cases were outliers with respect to the covariates. Respectively, 40 and 13 of them were influential. Fitting the model with or without the 53 influential cases changed the adjusted $R^{2}$ of the model from 0.43 to 0.51 . In adults, 67 cases were outliers with respect to the biomarker values and 50 cases with respect to the covariates. Respectively, 54 and 14 of them were found to be influential. Exclusion of the 68 influential cases resulted in an adjusted $R^{2}$ of 0.38 compared with an adjusted $R^{2}$ of 0.30 with influential cases. Thus, identification and exclusion of influential cases in multiple regression models will lead to better prediction models, with an higher proportion of the variability explained. Also, exclusion of influential outliers sometimes changed the regression coefficients (but not the sign) of the covariates and had an influence on the covariates that were retained as significant $(p<0.05)$ in the model. When we exclude influential cases, these models will be better applicable to the general population, and are therefore preferential for studies in which we want to extrapolate general guidelines for human biomonitoring.

\subsection{Determinants of serum $P C B s, H C B$ and $p, p^{\prime}-D D E$}

For all age groups separately, we constructed multiple linear regression models with PCAHs expressed in $\mathrm{nmol} / \mathrm{L}$ and without influential outliers in order to identify the factors that determine inter-individual variability in the serum levels of each of the three PCAHs. For serum PCBs, the model explained 39.1\%, 50.8\% and $38.0 \%$ of the variability in, respectively newborns, adolescents and adults (Fig. 1). For the chlorinated pesticides, the total variability explained was lower than in PCBs and amounted in the three age groups to, respectively $21.5 \%, 26.0 \%$ and $43.0 \%$ for $\mathrm{HCB}$, and to $22.1 \%, 27.9 \%$ and $26.0 \%$ for $\mathrm{p}, \mathrm{p}^{\prime}$-DDE. The factors that contributed most to the variability were blood fat, age, sex, BMI, change in body weight, area of residence and local meat consumption (Fig. 1).

\subsection{Quantification of impact of determinants}

Starting from the multiple linear regression models, we used the estimates of the regression coefficients to quantify the 
Table 1

Descriptive statistics in three age groups.

\begin{tabular}{|c|c|c|c|c|}
\hline & & Mothers and newborns ${ }^{a}$ & Adolescents & Adults \\
\hline$N$ & & 1169 & 1679 & 1583 \\
\hline Sex & Female/male & $1196 / 0$ & $792 / 887$ & $808 / 775$ \\
\hline \multirow[t]{2}{*}{ Age (years) } & Mean $\pm S D$ & $29.6 \pm 4.3$ & $14.9 \pm 0.5$ & $57.6 \pm 4.1$ \\
\hline & Range & $18.1-44.0$ & $13.8-16.5$ & $49.8-65.3$ \\
\hline \multirow[t]{2}{*}{ BMI } & Mean \pm SD & $23.3 \pm 4.2$ & $20.6 \pm 3.1$ & $26.9 \pm 4.2$ \\
\hline & Range & $14.0-44.6$ & $13.7-36.6$ & $15.1-48.1$ \\
\hline \multirow[t]{3}{*}{ Smoking } & $\%$ non-smokers & 64.2 & 86.4 & 44.6 \\
\hline & $\%$ former smokers & 19.6 & - & 37.2 \\
\hline & $\%$ current smokers & 16.2 & 13.6 & 18.3 \\
\hline Blood fat in $\mathrm{mg} / \mathrm{dL}$ & $\begin{array}{l}\text { Mean } \\
(95 \% \mathrm{CI})\end{array}$ & $\begin{array}{l}209 \\
(205-213)\end{array}$ & $\begin{array}{l}444 \\
(440-448)\end{array}$ & $\begin{array}{l}612 \\
(604-620)\end{array}$ \\
\hline \multirow[t]{2}{*}{ Serum PCBs in $\mathrm{nmol} / \mathrm{L}$} & $\begin{array}{l}\text { Geometric mean } \\
(95 \% \mathrm{CI})\end{array}$ & $\begin{array}{l}0.333 \\
(0.318-0.349)\end{array}$ & $\begin{array}{l}0.781 \\
(0.762-0.801)\end{array}$ & $\begin{array}{l}5.485 \\
(5.370-5.603)\end{array}$ \\
\hline & Number $(\%)<$ LOD & 369 (31.6\%) & $19(1.1 \%)$ & $2(0.1 \%)$ \\
\hline Serum PCBs in $\mathrm{pmol} / \mathrm{g}$ fat & $\begin{array}{l}\text { Geometric mean } \\
(95 \% \mathrm{CI})\end{array}$ & $\begin{array}{l}226 \\
(215-236)\end{array}$ & $\begin{array}{l}178 \\
(174-183)\end{array}$ & $\begin{array}{l}919 \\
(901-937)\end{array}$ \\
\hline \multirow[t]{2}{*}{ Serum HCB in $\mathrm{nmol} / \mathrm{L}$} & $\begin{array}{l}\text { Geometric mean } \\
(95 \% \mathrm{CI})\end{array}$ & $\begin{array}{l}0.189 \\
(0.180-0.198)\end{array}$ & $\begin{array}{l}0.364 \\
(0.358-0.370)\end{array}$ & $\begin{array}{l}1.370 \\
(1.329-1.412)\end{array}$ \\
\hline & Number $(\%)<$ LOD & $253(21.6 \%)$ & $0(0.0 \%)$ & $0(0.0 \%)$ \\
\hline \multirow[t]{2}{*}{ Serum HCB in $\mathrm{pmol} / \mathrm{g}$ fat } & Geometric mean & 101 & 87.9 & 273 \\
\hline & $(95 \% \mathrm{CI})$ & $(95-106)$ & $(86.4-89.4)$ & $(264-281)$ \\
\hline \multirow[t]{3}{*}{ Serum $\mathrm{p}, \mathrm{p}^{\prime}-\mathrm{DDE}$ in $\mathrm{nmol} / \mathrm{L}$} & Geometric mean & 0.993 & 1.462 & 8.885 \\
\hline & $(95 \% \mathrm{CI})$ & $(0.929-1.056)$ & $(1.404-1.522)$ & (8.441-9.352) \\
\hline & Number $(\%)<$ LOD & $20(1.7 \%)$ & $1(0.1 \%)$ & $5(0.3 \%)$ \\
\hline \multirow[t]{2}{*}{ Serum $\mathrm{p}, \mathrm{p}^{\prime}-\mathrm{DDE}$ in $\mathrm{pmol} / \mathrm{g}$ fat } & Geometric mean & 515 & 529 & 2341 \\
\hline & $(95 \% \mathrm{CI})$ & $(481-548)$ & $(486-572)$ & $(2202-2479)$ \\
\hline
\end{tabular}

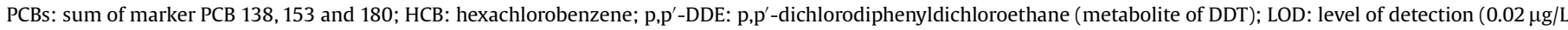
for all compounds).

a Mother and newborn study: sex, age, BMI and smoking of the mother are given; blood and serum values of the cord blood are given.

Table 2

Adjusted $R^{2}$ of multiple linear regression models ${ }^{\mathrm{a}}$ with different units of serum PCBs as dependent variable.

\begin{tabular}{lll}
\hline & Adolescents & Adults \\
\hline (A) Volume-based units of serum PCBs & $R_{\mathrm{a}}^{2}=0.3860$ & $R_{\mathrm{a}}^{2}=0.1602$ \\
$\begin{array}{ll}\text { (B) Volume-based units of serum PCBs with } \\
\quad \text { adjustment for blood fat }\end{array}$ & $R_{\mathrm{a}}^{2}=0.4281$ & $R_{\mathrm{a}}^{2}=0.2990$ \\
(C) Fat-based units of serum PCBs & $R_{\mathrm{a}}^{2}=0.4443$ & $R_{\mathrm{a}}^{2}=0.1862$ \\
\hline
\end{tabular}

a The multiple regression model was adjusted for the following covariates: in adolescents: BMI, sex, educational level of the family, breastfeeding, smoking during pregnancy of the mother, age mother at childbirth, study area, local meat consumption, eel fat consumption, animal fat consumption and milk fat consumption (only for A); in adults: age, smoking, change in body weight, BMI (only for C), study area, local meat consumption (only for B and C), eel fat consumption, mussel fat consumption, chicken fat consumption, vegetable fat consumption (only for C), consumption of liver fat (only for A) and alcohol use (only for C).

relationship between the biomarkers of exposure and significant determinants at the $5 \%$ level (Table 3 ).

We found a highly consistent relationship between changes in the blood fat content and variations in the serum concentration of the three fat-soluble pollutants. In peripheral serum (adolescents and adults), an increase of the blood fat content with $100 \mathrm{mg} / \mathrm{dL}$ was associated with a $11-14 \%$ increase $(p<0.001)$ in the concentration of PCBs, HCB or p, $\mathrm{p}^{\prime}$-DDE. In cord plasma, the variation among the three markers was higher with increases between $11 \%$ and $23 \%(p<0.001)$ for an augmentation of the blood fat content with $100 \mathrm{mg} / \mathrm{dL}$.
Both in mothers and adults, there was a strong association between the age of the respondent and the serum/plasma concentration of all three persistent compounds. Increases in the serum levels of the three PCAHs were highly consistent in $50-65$-year-old adults (+11-14\% per 5-year increase of age, $p<0.001)$ and more diverse in 18-40-year-old mothers $(+18-34 \%$ per 5 -year increase of age, $p<0.001)$. As the age range in adolescents was only 2.7 years, it was not surprising to find a weak relationship between the PCAHs concentration and age; we only found a significant $(p<0.01)$ association between serum HCB and the adolescents' age. On the other hand, the serum PCB concentration at the age of $14-16$ years was significantly $(p<0.01)$ influenced by the age of the mother at the adolescent's birth. Also, birth weight of the adolescent was associated with HCB levels and the event of being breastfed as a baby had a major impact on the serum concentration of all three PCAHs of the teenager. Compared to adolescents who only received formula, those who were breastfed had $7 \%, 26 \%$ and $32 \%$ higher serum concentrations of, respectively $\mathrm{HCB}, \mathrm{PCBs}$ and $\mathrm{p}, \mathrm{p}^{\prime}-\mathrm{DDE}$ (all $p<0.001$ ).

With respect to sex, we found different effects in the various age groups. In adults, serum levels of $\mathrm{p}, \mathrm{p}^{\prime}$-DDE and HCB were, respectively $28 \%$ and $40 \%(p<0.001)$ higher in women compared to men, while serum PCBs did not differ significantly between men and women. In adolescents, we found $20-40 \%(p<0.001)$ higher serum levels in boys compared to girls for all three PCAHs. Also for BMI, the results varied by age. In adults, serum levels of p,p'-DDE and HCB (but not PCB) were significantly and positively related to $\mathrm{BMI}$, while in adolescents, the serum levels of all three PCAHs decreased significantly when BMI was rising. In the mothers of the newborns, we found contradicting results, i.e. 

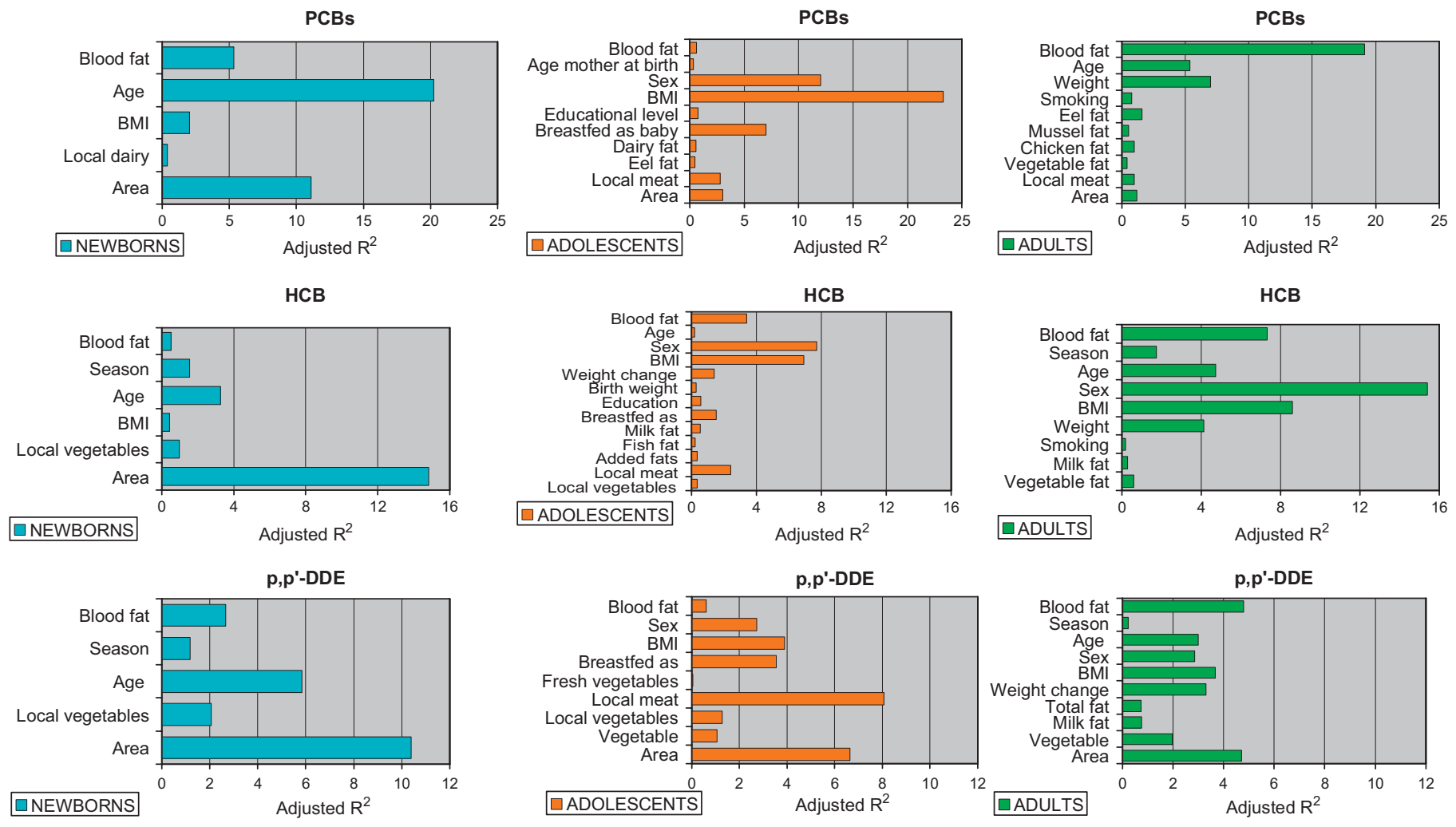

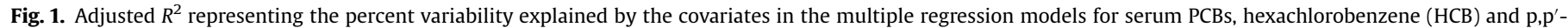
DDE in three age classes.

BMI was negatively associated with serum PCBs and positively with serum HCB. For different age groups and PCAHs, however, we found very consistent relationships between changes in body weight and serum levels of persistent compounds: a weight gain of $10 \mathrm{~kg}$ was associated with a decrease in the serum levels of PCBs, HCB or p, $\mathrm{p}^{\prime}$-DDE up to $24 \%$.

In the mothers of the newborns, no associations were found between the food intake pattern of the last year before pregnancy and serum levels of PCAHs in cord blood. In adolescents, a positive association was found between serum PCBs, HCB or p, $\mathrm{p}^{\prime}$-DDE on the one hand and different sources of animal fat (dairy fat, fish fat and added fats) on the other hand. The serum level of p, $\mathrm{p}^{\prime}$-DDE was positively associated with fresh vegetable consumption in adolescents. In adults between 50 and 65 years old, a positive association was detected between animal fat intake (eel, mussels, chicken) and serum PCB levels. Contradictory, both total fat and milk fat were associated negatively with serum levels of HCB or $\mathrm{p}, \mathrm{p}^{\prime}$-DDE in adults.

Over and beyond food intake we studied the effect of locally grown food products on serum levels of PCAHs. In mothers of newborns, consumption of local dairy products was associated with higher serum PCB levels. In adolescents, consumption of local meat was related to higher levels of all three PCAHs. In all age groups, local vegetable consumption and/or being owner of a vegetable garden was associated with increased serum levels of the persistent pesticides.

Finally, a number of variables show small effects in some age groups and for some exposure markers. Smoking was identified as confounder in adults for PCBs and for $\mathrm{HCB}$, but the results were inconsistent and the impact was small. In adolescents, a higher educational level of the respondent itself was significantly associated with higher serum levels of HCB; the educational level of the family (highest of mother or father) was significantly and positively related to serum PCBs of the adolescent. In adults and mothers, significantly higher values of $\mathrm{HCB}$ and p,p'-DDE were found in the winter season.

\section{Discussion}

In this study, we determined the major covariates of the serum levels of marker PCBs, HCB and p, $\mathrm{p}^{\prime}$-DDE in three different age groups. We found consistent relationships between the serum concentration of the three fat-soluble pollutants and blood fat, age, changes in body weight and sources of animal fat in the diet. The serum levels of the two persistent pesticides were positively associated with local vegetable consumption. In 14-15-year-old adolescents, being breastfed as a baby was an important predictor of serum levels of PCAHs during puberty. The impact of sex and BMI differed by age. We also showed that exclusion of influential outliers in multiple linear regression models resulted in multiple regression models that are better applicable to the general population. The regression model with the pollutant expressed in volume-based units and blood fat as a separate independent variable was superior compared to models with other units in terms of adjusted $R^{2}$.

Up to now, there is no general agreement in literature on the use of units for biomarkers assessing exposure to persistent pollutants. In some studies, concentrations (mol/L) are reported, while others use fat-based units ( $\mathrm{mol} / \mathrm{g}$ blood fat). In this study, we could explain more of the observed variability (highest adjusted $R^{2}$ ) if PCAHs were expressed as volume-based units and blood fat was included as an explanatory variable in the model. Results were only presented for PCBs, but similar conclusions can be drawn for the chlorinated pesticides, HCB and $\mathrm{p}, \mathrm{p}^{\prime}$-DDE (data not shown). For all three components, the relation between the serum concentration and the blood fat content was highly consistent: an increase of the blood fat content 
Table 3

Quantification of determinants of serum PCBs, hexachlorobenzene (HCB) and p,p'-DDE.

\begin{tabular}{|c|c|c|c|c|c|c|c|c|c|c|}
\hline & & \multicolumn{3}{|c|}{$\begin{array}{l}\text { Mothers and newborns cord } \\
\text { plasma }\end{array}$} & \multicolumn{3}{|c|}{ Adolescents peripheral serum } & \multicolumn{3}{|c|}{ Adults peripheral serum } \\
\hline & & PCBs & HCB & $\begin{array}{l}\mathrm{p}, \mathrm{p}^{\prime}- \\
\mathrm{DDE}\end{array}$ & PCBs & HCB & $\begin{array}{l}\mathrm{p}, \mathrm{p}^{\prime}- \\
\mathrm{DDE}\end{array}$ & PCBs & HCB & $\begin{array}{l}\mathrm{p}, \mathrm{p}^{\prime}- \\
\mathrm{DDE}\end{array}$ \\
\hline \multicolumn{11}{|c|}{$\begin{array}{l}\text { \% change in biomarker concentration for a given change of the covariate } \\
\text { Covariates related to blood sampling }\end{array}$} \\
\hline Blood fat & $+100 \mathrm{mg} / \mathrm{dL}$ & $+23 \% * * *$ & $+11 \% * * *$ & $+20 \% * * *$ & $+14 \% * * *$ & $+11 \% * * *$ & $+11 \% * * *$ & $+11 \% * * *$ & $+10 \% * * *$ & $+12 \% * * *$ \\
\hline Season & $\begin{array}{l}\text { Spring vs. winter } \\
\text { Summer vs. winter } \\
\text { Autumn vs. winter }\end{array}$ & $\begin{array}{l}\text { ns } \\
\text { ns } \\
\text { ns }\end{array}$ & $\begin{array}{l}-20 \% * * * \\
-18 \% * * \\
-19 \% * *\end{array}$ & $\begin{array}{l}-23 \% * * * \\
-18 \% * * \\
\text { ns }\end{array}$ & $\begin{array}{l}\text { ns } \\
\text { ns } \\
\text { ns }\end{array}$ & $\begin{array}{l}\text { ns } \\
\text { ns } \\
\text { ns }\end{array}$ & $\begin{array}{l}\text { ns } \\
\text { ns } \\
\text { ns }\end{array}$ & $\begin{array}{l}\text { ns } \\
- \\
\text { ns }\end{array}$ & $\begin{array}{l}-17 \% * * * \\
- \\
\text { ns }\end{array}$ & $\begin{array}{l}-14 \% * * \\
- \\
\text { ns }\end{array}$ \\
\hline \multicolumn{11}{|l|}{ Biological covariates } \\
\hline Age & +5 years & $+34 \% * * *$ & $+18 \% * * *$ & $+24 \% * * *$ & ns & $+5 \% * * a$ & ns & $+11 \% * * *$ & $+14 \% * * *$ & $+14 \% * * *$ \\
\hline Sex & Male vs. female & - & - & - & $+40 \% * * *$ & $+20 \% * * *$ & $+26 \% * * *$ & ns & $-40 \% * * *$ & $-28 \% * * *$ \\
\hline BMI & $+5 \mathrm{~kg} / \mathrm{m}^{2}$ & $-15 \%^{* * *}$ & $+6 \%^{*}$ & ns & $-40 \% * * *$ & $-14 \%^{* * *}$ & $-24 \%^{* * *}$ & ns & $+24 \%^{* * *}$ & $+22 \% * * *$ \\
\hline Weight change & $+10 \mathrm{~kg}$ & ns & ns & ns & ns & $-7 \% * * * \mathrm{~b}$ & ns & $-14 \%^{* * *}$ & $-19 \% * * *$ & $-24 \% * * *$ \\
\hline Birth weight & $+1 \mathrm{~kg}$ & - & - & - & ns & $+3 \% *$ & ns & - & - & - \\
\hline Age of mother at birth & +5 years & - & - & - & $+3 \%^{* *}$ & ns & ns & - & - & - \\
\hline \multicolumn{11}{|l|}{ Socio-economic covariates } \\
\hline $\begin{array}{l}\text { Highest educational level of the family } \\
\text { (mother or father) }\end{array}$ & $\begin{array}{l}\text { Primary vs. higher } \\
\text { Low secondary vs. } \\
\text { higher } \\
\text { High secondary vs. } \\
\text { higher }\end{array}$ & ns & ns & ns & $\begin{array}{l}-19 \%^{*} \\
-10 \% * * * \\
-4 \%^{*}\end{array}$ & ns & ns & ns & ns & ns \\
\hline Secondary school level of the adolescent & $\begin{array}{l}\text { Technical vs. } \\
\text { general } \\
\text { Vocational vs. } \\
\text { general }\end{array}$ & - & - & - & ns & $\begin{array}{l}-4 \% * \\
-7 \% * *\end{array}$ & ns & - & - & - \\
\hline \multicolumn{11}{|l|}{ Life style } \\
\hline \multirow[t]{2}{*}{ Smoking } & $\begin{array}{l}\text { Former vs. non- } \\
\text { smoker }\end{array}$ & ns & ns & ns & - & - & - & ns & $-6 \% *$ & ns \\
\hline & $\begin{array}{l}\text { Current vs. non- } \\
\text { smoker }\end{array}$ & ns & ns & ns & ns & ns & ns & $+10 \% * * *$ & ns & ns \\
\hline Breastfed as baby & Yes vs. no & - & - & - & $+26 \% * * *$ & $+7 \%^{* * *}$ & $+32 \% * * *$ & - & - & - \\
\hline \multicolumn{11}{|l|}{ Food intake } \\
\hline Total fat & +10 g/day & ns & ns & ns & ns & ns & ns & ns & ns & $-10 \% * *$ \\
\hline Milk fat & +5 g/day & ns & ns & ns & $+1.3 \% * *$ & $+4 \% * *$ & ns & ns & $-7 \% * *$ & $-14 \% * *$ \\
\hline Fish fat (all fish) & $+5 \mathrm{~g} /$ day & ns & ns & ns & ns & $+6 \% *$ & ns & ns & ns & ns \\
\hline Eel fat & $+0.1 \mathrm{~g} /$ day & ns & ns & ns & $+1.0 \% *$ & ns & ns & $+1.3 \% * * *$ & ns & ns \\
\hline Mussel fat & $+0.1 \mathrm{~g} /$ day & ns & ns & ns & ns & ns & ns & $+4 \% * *$ & ns & ns \\
\hline Chicken fat & $+0.1 \mathrm{~g} /$ day & ns & ns & ns & ns & ns & ns & $+1 \% *$ & ns & ns \\
\hline Added fats ${ }^{c}$ & $+5 \mathrm{~g} /$ day & ns & ns & ns & ns & $+1.3 \% * *$ & ns & ns & ns & ns \\
\hline Fresh vegetables & $+100 \mathrm{~g} /$ day & ns & ns & ns & ns & ns & $+2 \% *$ & ns & ns & ns \\
\hline \multicolumn{11}{|l|}{ Local food consumption } \\
\hline Local meat & Yes vs. no & ns & ns & ns & $+16 \% * * *$ & $+7 \% * *$ & $+19 \% * * *$ & $+10 \% * * *$ & ns & ns \\
\hline Local dairy & Yes vs. no & $+11 \% *$ & ns & ns & ns & ns & ns & ns & ns & ns \\
\hline Local vegetables & Yes vs. no & ns & $+12 \% *$ & $+18 \% * *$ & ns & $+6 \% * *$ & $+13 \% *$ & ns & ns & ns \\
\hline Vegetable garden & Yes vs. no & ns & ns & ns & ns & ns & $+14 \% * * *$ & ns & ns & $+11 \% *$ \\
\hline
\end{tabular}

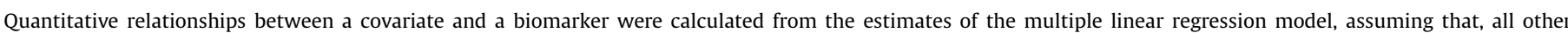

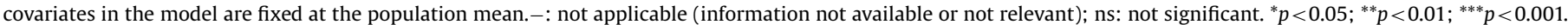

${ }^{a}$ For increase of age with 1 year.

b For weight change of $5 \mathrm{~kg}$.

${ }^{\mathrm{c}}$ Added fats $=$ spreading and cooking fats.

by $100 \mathrm{mg} / \mathrm{dL}$ was associated with a $10-14 \%$ higher concentration of PCAHs in peripheral serum (both in adolescents and in adults), and a $11-23 \%$ higher concentration in cord blood. Therefore, for multiple regression analysis of PCBs or chlorinated pesticides, we recommend to use the values expressed as volume-based units $(\mathrm{nmol} / \mathrm{L})$ with blood fat added as a separate independent variable in the model. This approach allows the serum concentrations of persistent pollutants to be appropriately adjusted for blood fat, and the statistical significance of other variables in the model to be independent of effects of blood fat concentrations. These recommendations are in line with guidelines for the use of creatinine in measurements of urinary biomarkers by Barr et al. (2005). Their advice for biologic monitoring measurements in spot urine is to use the urinary analyte concentration and add creatinine as a separate value in the multiple regression model. Urinary creatinine concentrations are used to adjust for dilution of spot urine samples, and thus are comparable to the use of blood fat as dilution marker for non-fasting serum or plasma. 
The levels reported in this study are in line with former measurements of serum levels of PCBs, HCB and p,p'-DDE in Flanders. In 1999, 200 17-18-year-old adolescents and 200 adult women between the age of 50 and 65 were studied in a pilot trial for human biomonitoring. The geometric mean of the summed PCBs in the youngsters was $293 \mathrm{pmol} / \mathrm{g}$ fat (Staessen et al., 2001), which is considerably higher compared to the current study (i.e. $178 \mathrm{pmol} / \mathrm{g}$ fat). The higher values in the pilot trial can be explained by two independent factors. First, the teenagers in the pilot trial were on average 3 years older and levels of persistent pollutants are known to increase with age. Second, the adolescents in the pilot trial were studied on average 5 years earlier in time, when levels of PCBs in the environment were still higher. Studies in breast milk have shown that levels of PCBs have decreased by $80-90 \%$ over a period of 12 years (Van Leeuwen and Malisch, 2002; Schade and Heinzow, 1998). In the pilot project, median levels in 200 women equaled $1054 \mathrm{pmol} / \mathrm{g}$ fat for PCBs, $442 \mathrm{pmol} / \mathrm{g}$ fat for HCB and $2736 \mathrm{pmol} / \mathrm{g}$ fat for p,p'-DDE (Koppen et al., 2002). These levels are also higher than the average values measured in the current study, that is 919, 273 and $2341 \mathrm{pmol} / \mathrm{g}$ fat, respectively. Possible explanations for the lower values in the current trial are the decreasing levels in the environment and the fact that in the pilot project only women were studied, which may result in higher values for this age class.

In most studies, the major determinant of biomarkers that reflect persistent pollutants is the age of the respondent (Schade and Heinzow, 1998; Dallaire et al., 2002; Falk et al., 1999; Jonsson et al., 2005; Solomon and Weiss, 2002; Sweeney et al., 2001). In the current study, we also found a highly consistent relationship between biomarkers of exposure and age in 50-65-year-old adults $\left(+11 \%\right.$ for $\mathrm{PCBs},+14 \%$ for $\mathrm{HCB}$ and $+14 \%$ for $\mathrm{p}, \mathrm{p}^{\prime}$-DDE per 5 -year increase of age), while the effects were less constant in $18-40$-year-old pregnant women $(+34 \%,+18 \%$ and $+24 \%$, respectively). Possibly, other factors such as parity or previous breastfeeding, although not identified as significant determinant, may interact with age in young mothers. The age dependency can be explained by larger buildup of PCAHs in the body throughout life. Moreover, as environmental loads of PCAHs are decreasing over time, older people have been exposed to higher levels in the past.

In adolescents, serum PCAHs were negatively related to BMI, while a positive relationship with BMI was observed in adults. These findings are in accordance with earlier studies in youngsters (Nawrot et al., 2002; Ryan et al., 1994) and in adults (Schade and Heinzow, 1998; Falk et al., 1999; Jonsson et al., 2005). In adults, we expect a positive relationship in view of the higher absolute body burden in obese subjects and the assumption of a steady state between PCAH concentration in fat tissue and in serum. In adolescents, a transient dilution effect in adipose tissue during growth spurt may explain the negative relationship between serum PCAH levels and BMI. As body fat content in teenager girls is about double that of boys in adolescence, the same mechanism may explain the lower serum values in girls compared to boys. Also the negative relationship between changes in body weight and serum levels of PCAHs is in line with this mechanism. Weight loss and lipolysis may lead to an up-concentration of PCAHs in the lipid tissue and subsequently, if we accept the assumption of steady state between fat tissue and serum, to higher serum values of PCAHs.

Nutrition is a major source of exposure to PCAHs. In mothers of newborns, we found no significant associations between serum levels of PCAHs and food consumption in the year before the pregnancy. Although this best represents the 'usual' food intake, the relationship between serum levels and food consumption is probably troubled by the long time gap, by changing food habits during pregnancy and possibly also by a changing metabolism during pregnancy. In adolescents, the serum levels of PCAHs at the age of 14-16 years were associated with the use of breastfeeding as baby. This observation has been reported several times in the last decade and in different Western countries (Schade and Heinzow, 1998; Falk et al., 1999; Jonsson et al., 2005; Solomon and Weiss, 2002; Nawrot et al., 2002; Glynn et al., 2007; Grimvall et al., 1997). Still, according to WHO guidelines, mother's milk remains the best nutrition for a baby (WHO, 2001). With some exceptions, we can state that both in adolescents and in adults, serum levels of PCAHs were positively related to animal food intake (meat, chicken or fish). This is in accordance with literature (Falk et al., 1999; Glynn et al., 2003, 2007; He et al., 2001) and with the fact that animal fats are the major source of fat-soluble bio-accumulating pollutants. The serum levels of the chlorinated pesticides (but not PCBs) were positively associated with local vegetable consumption and/or with being owner of a vegetable garden. This indicates that there may be local contamination, either as a result of former use of DDT and HCB in the area, or even due to current illegal or ignorant use of these products in Flanders. As a result of the current human biomonitoring study, the government has launched a campaign to collect old pesticides through the local community authorities.

Finally, a number of variables that are associated with the serum levels of PCAHs, are probably no determining factor in itself but rather a dummy for other underlying factors that determine exposure to or metabolism of the persistent compounds. Smoking was identified as confounder in adults, but the results were inconsistent and the impact was small. Possibly, there is colinearity between smoking and other life style factors such as nutrition, or social class. In adolescents, a higher educational level of the respondent itself was significantly associated with higher serum levels of HCB; the educational level of mother or father was significantly and positively related to serum PCBs. It is likely that educational level is associated with nutritional habits (e.g. fish or milk consumption), living conditions, or other life style factors that may influence exposure to persistent compounds. The serum concentrations of HCB and p,p'-DDE differed by season. In adults and mothers, significantly higher values were found in the winter season. We can hypothesize that this may be due to nutritional factors (e.g. higher animal fat consumption in winter) or to differences in body composition (e.g. weight gain in winter).

A major strength of this study was the availability of a large data set (more than 4400 individuals) for three different biomarkers of the same chemical class in different age classes (from newborn to adults). The chemical measurements, the collection of the questionnaire data, the calculation of secondary variables and the statistical analyses were performed in a consistent and uniform method for the three biomarkers and the three age groups. This has resulted in high-quality data and thus allows to generalize the findings and deduct a number of recommendations for human biomonitoring studies on how to handle outliers, use of units and selection of major confounders. The data show that methodological aspects and host factors are important to take into account in human biomonitoring studies that perform between-group comparisons or describe relations between internal PCAH exposure and health effects.

Although the results are based on a large data set, the conclusions are still limited to the three biomarkers at exposure levels that were assessed in this study and to the age ranges of the subgroups that were included in the study. To further improve our insight in the determinants of variability in these and other biomarkers and the methodological aspects of human biomonitoring studies, we need well-designed studies with large and welldocumented gradients in environmental, biological and life style factors. A European human biomonitoring project, enabling comparison of biomarker data and information on covariates of citizens of different countries could meet these requirements. 


\section{Acknowledgments}

This study was supported by a grant of the Long Range Research Initiative (LRI) of Cefic (HETRA D2.2).

The Flemish Environment and Health Study was commissioned, financed and steered by the Flemish Community (Department of Science, Department of Public Health, Department of Environment), without any responsibility for the scientific content.

\section{References}

Barr, D.B., Wilder, L.C., Caudill, S.P., Gonzalez, A.J., Needham, L.L., Pirkle, J.L., 2005. Urinary creatinine concentrations in the US population: implications for urinary biologic monitoring measurements. Environ. Health Perspect. 113, 192-200.

Becker, K., Müssig-Zufika, M., Conrad, A., Lüdecke, A., Schulz, C., Seiwert, M., et al., 2008. German Environmental Survey for Children 2003/06. GerES IV-Human Biomonitoring. Federal Environment Agency (UBA), Berlin, Germany.

Bilau, M., Matthys, C., Baeyens, W., Bruckers, L., De Backer, G., Den Hond, E., et al., 2008. Dietary exposure to dioxin-like compounds in three age groups: results from the Flemish environment and health study. Chemosphere 70, 584-592.

Covaci, A., Voorspoels, S., Thomsen, C., van Bavel, B., Neels, H., 2006. Evaluation of total lipids using enzymatic methods for the normalization of persistent organic pollutant levels in serum. Sci. Total Environ. 366, 361-366.

Dallaire, F., Dewailly, E., Laliberté, C., Muckle, G., Ayotte, P., 2002. Temporal trends of organochlorine concentrations in umbilical cord blood of newborns from the lower north shore of the St. Lawrence River (Québec, Canada). Environ. Health Perspect. 110 (8), 835-838.

Den Hond, E., Roels, H.A., Hoppenbrouwers, K., Nawrot, T., Thijs, L., Vandermeulen, C., et al., 2002. Sexual maturation in relation to polychlorinated aromatic hydrocarbons: Sharpe and Skakkebaek's hypothesis revisited. Environ. Health Perspect. 110 (8), 771-776.

Falk, C., Hanrahan, L., Anderson, H.A., Kanarek, M.S., Draheim, L., Needham, L., et al., 1999. Body burden levels of dioxin, furans, and PCBs among frequent consumers of Great Lakes sport fish. The Great Lakes Consortium. Environ. Res. 80 (2 Part 2), S19-S25.

Glynn, A., Aune, M., Darnerud, P.O., Cnattingius, S., Bjerselius, R., Becker, W., et al., 2007. Determinants of serum concentrations of organochlorine compounds in Swedish pregnant women: a cross-sectional study. Environ. Health 6, 2.

Glynn, A.W., Granath, F., Aune, M., Atuma, S., Darnerud, P.O., Bjerselius, R., et al., 2003. Organochlorines in Swedish women: determinants of serum concentrations. Environ. Health Perspect. 111 (3), 349-355.

Gomara, B., Ramos, L., Gonzalez, M.J., 2002. Determination of polychlorinated biphenyls in small-size serum samples by solid-phase extraction followed by gas chromatography with micro-electron-capture detection. J. Chromatogr. 766, 279-728.

Grimvall, E., Rylander, L., Nilsson-Ehle, P., Nilsson, U., Stromberg, U., Hagmar, L., et al., 1997. Host and environmental determinants of polychlorinated aromatic hydrocarbons in serum of adolescents. Arch. Environ. Contam. Toxicol. 32 (3), 329-336.
Grubbs, F., 1969. Procedures for detecting outlying observations in samples. Technometrics 11 (1), 1-21.

He, J.P., Stein, A.D., Humphrey, H.E., Paneth, N., Courval, J.M., 2001. Time trends in sport-caught Great Lakes fish consumption and serum polychlorinated biphenyl levels among Michigan Anglers, 1973-1993. Environ. Sci. Technol. 35 (3), 435-440.

Jonsson, B.A., Rylander, L., Lindh, C., Rignell-Hydbom, A., Giwercman, A., Toft, G. et al., 2005. Inter-population variations in concentrations, determinants of and correlations between 2,2',4,4',5,5'-hexachlorobiphenyl (CB-153) and 1,1-dichloro-2,2-bis ( $\mathrm{p}$-chlorophenyl)-ethylene (p,p'-DDE): a cross-sectional study of 3161 men and women from Inuit and European populations. Environ. Health 4, 27.

Koppen, G., Covaci, A., Van Cleuvenbergen, R., Schepens, P., Winneke, G., Nelen, V. et al., 2002. Persistent organochlorine pollutants in human serum of 50-65 years old women in the Flanders Environmental and Health Study (FLEHS) Part 1: Concentrations and regional differences. Chemosphere 48 (8), 811-825.

Moore, D.S., McCabe, G.P., 1999. The Introduction to the Practice of Statistics, third ed. W.H. Freeman and Company, New York.

Lauwerys, R., Hoet, P., 2001. Industrial Chemical Exposure: Guidelines for Biological Monitoring. Lewis Publishers, CRC Press, Boca Raon, FL.

Nawrot, T.S., Staessen, J.A., Den Hond, E.M., Koppen, G., Schoeters, G., Fagard, R., et al., 2002. Host and environmental determinants of polychlorinated aromatic hydrocarbons in serum of adolescents. Environ. Health Perspect. 110, 583-589.

$\mathrm{NCEH}$, 2005. Third National Report on Human Exposure to Environmental Chemicals. National Center for Environmental Health ((NCEH)), Centers for Disease Control and Prevention (CDC), Atlanta, GA, USA.

Ryan, J.J., Hsu, C.C., Boyle, M.J., Guo, Y.L., 1994. Blood serum levels of PCDFs and PCBs in Yu-Cheng children peri-natally exposed to a toxic rice oil. Chemosphere 29, 1263-1278.

Schade, G., Heinzow, B., 1998. Organochlorine pesticides and polychlorinated biphenyls in human milk of mothers living in northern Germany: current extent of contamination, time trend from 1986 to 1997 and factors that influence the levels of contamination. Sci. Total Environ. 215 (1-2), 31-39.

Solomon, G.M., Weiss, P.M., 2002. Chemical contaminants in breast milk: time trends and regional variability. Environ. Health Perspect. 110, A339-A347.

Staessen, J.A., Nawrot, T., Den Hond, E., Thijs, L., Fagard, R., Hoppenbrouwers, K. et al., 2001. Renal function, cytogenetic measurements, and sexual development in adolescents in relation to environmental pollutants: a feasibility study of biomarkers. Lancet 357 (9269), 1660-1669.

Sweeney, A.M., Symanski, E., Burau, K.D., Kim, Y.J., Humphrey, H.E., Smithci, M.A. 2001. Changes in serum PBB and PCB levels over time among women of varying ages at exposure. Environ. Res. 86, 128-139.

Van Den Heuvel, R.L., Koppen, G., Staessen, J.A., Hond, E.D., Verheyen, G., Nawrot T.S., et al., 2002. Immunologic biomarkers in relation to exposure markers of PCBs and dioxins in Flemish adolescents (Belgium). Environ. Health Perspect. 110 (6), 595-600.

Van Leeuwen, F.X.R., Malisch, R., 2002. Results of the third round of WHOcoordinated exposure study on the levels of PCBs, PCDDs and PCDFs in human milk. Organohalogen Compounds 56, 311-316.

WHO, 2001. The optimal duration of exclusive breastfeeding. Report of an Expert Consultation, WHO

WHO, ., 1995. Physical Status: The Use and Interpretation of Anthropomethry. World Health Organisation, Geneva. 